\title{
An Online Learning System Based on Panoramic Technology for Sport Psychology
}

\author{
http://dx.doi.org/10.3991/ijet.v11i09.6115 \\ Wenxin $\mathrm{Xu}^{1}$, Jiwei Yao ${ }^{2}$ \\ ${ }^{1}$ Fujian Normal University, Fuzhou, Fujian, China \\ ${ }^{2}$ Hunan University of Science and Technology, Xiangtan, Hunan, China
}

\begin{abstract}
Traditional teaching mode cannot meet the learning needs of students. Online learning technology is increasingly accepted and has gradually become an important teaching mode. However, most online learning systems cannot achieve the panoramic effect. Moreover, students cannot be personally on the scene, such that it is difficult for them to focus. Particularly, some abstract course contents cannot be well expounded, which results in low learning efficiency. Thus, this study constructed an online learning system based on panoramic technology for sport psychology. This system synchronously performs explanation process, voice, and course data. This system can also reach the teaching purpose of panoramic simulation of a real classroom. In addition, this system has strong applicability. The experiment proves that students who learn with this system improve significantly in terms of course interest, theoretical knowledge understanding and wish, and practical application.
\end{abstract}

Index Terms-Panoramic mode, online learning system, Sport Psychology, teaching

\section{INTRODUCTION}

Sport psychology is a main specialized foundation course of school of physical education. Sport psychology mainly investigates psychological characteristics and change rules of people in sports [1]. Sport psychology is crucial for students in the school of physical education. Through learning sport psychology, students can master some of its professional knowledge, and improve training and competition results through adjusting psychological state in sports [2].

With the rapid development of information technology, more and more people learn the latest information from the Internet. Online learning system has become a new approach for people to enrich their knowledge. Online learning system regards students as the center. Without the restrictions of time, place, and playing times, it assists and supplements traditional teaching mode [3]. At present, online learning system of courses mainly depends on multimedia video teaching or pure text teaching [4]. Buttner [5] indicated that the application of online learning system promoted students' examination scores compared with controlled test questions and test performance in the previous semester before system application. June et al. [6] surveyed family-type online learning system and discussed the application of online video conference in primary school teaching. Results indicate that CHLS-VC can enhance learning process and cultivate the student-teacher interaction. A team investigated the model and its adapta- tion. The team gathered students' browsing behavior to update the student model and applied a multi-layer feedforward (MLFF) neural network to recognize students' cognitive styles inconspicuously [7]. Applying MLFF was due to its ability to understand data imprecisely or incompletely, generalize and learn from specific examples, and be quickly updated with extra parameters. The execution speed of MLFF also makes them ideal for real-time applications. Research shows that online learning system can extend students' learning duration and improve their learning effect.

However, although video teaching is vivid, the problem of recording distance exists. Thus, students feel distant for the contents being played, such that they cannot focus and then become uninterested [8]. In addition, this system lacks real-time student-teacher interaction. Some abstract course contents cannot be well explained, such that it is difficult for students to master the knowledge of sport psychology within limited class hours [9]. Moreover, the volume of psychology is large, such that it occupies much time and disk space to download and save it, which brings inconvenience. The teaching mode of pure text is too dull, and students learn elusive knowledge points with much difficulty.

This study designs an online learning system of panoramic mode to solve the defects of the existing teaching method. The system is operated through a matched special pen. With this system, teachers cannot just make a panoramic courseware, but also carry out remote live teaching and learning exchange, and on-site experiment teaching without time and place restrictions. Through this system, students can personally enter a learning environment and experience psychological changes in sports. They can also learn something difficult in a simple way, such that they can grasp sport psychology better. Furthermore, with this system, students can study during and after class, which improves their learning efficiency.

\section{OVERVIEW OF ONLINE LEARNING SYSTEM BASED ON PANORAMIC TECHNOLOGY}

This learning system is based on panoramic technology. This learning system aims to help teachers and students improve efficiency and overall mobilize all teaching resources in teaching activity to simulate a real classroom setup panoramically and prompt students' enthusiasm to the greatest extent. The advantages of this system are as follows:

()1 This learning system is online without time and space limitations, such that one-to-one communication can be achieved more easily. 
PAPER

AN ONLINE LEARning System BASEd On PANORAMIC TEChNOLOGY FOR SPORT Psychology

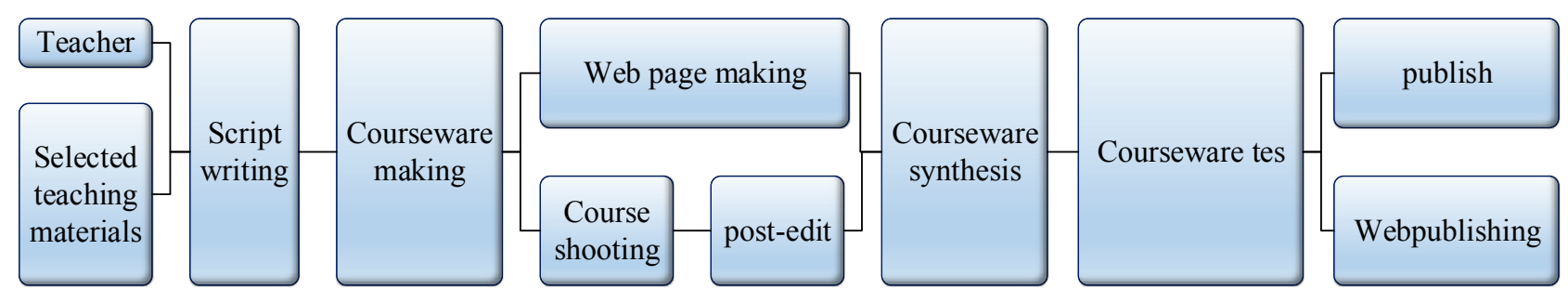

Figure 1. Simple process chart of panoramic courseware making system

(2) The system is easy to operate. After downloading the client, students can register an account number and then use it.

(3) Through the making system of the panoramic courseware, teachers can make an electronic courseware. The system makes the explained movements, voice, and course data into a standard courseware that complies with teaching and making norms.

(4) This system can make the teachers' voice, course data, and explained movements reappear through recording or live playing to reach the purpose of panoramic simulation of a classroom setting. This system offers a teaching mode that combines online and offline teaching.

(5) This system records teachers' voice technically and their explanation process synchronously, which are saved through a special data structure. Students can repeat the recordings and learn information effectively. In addition, the volume is considerably small. A 40 min course, including blackboard writing and voice, only occupies approximately $10 \mathrm{MB}$.

(6) This learning system has a panoramic laboratory system and presents micro or macro process-type or result-type experiment phenomena in the form of real-time calculation and animation.

(7) This system implements assignment interaction system. Teachers may arrange homework through the system, and students can answer questions and submit them through a panoramic learning pen. Then, teachers can correct and grade students' homework. These operations can be conducted via network. The system solves time and space limitation of teachers and students and saves many papers while ensuring learning effect.

\section{FunCtion Module Design Of ONLINE LEARNING SYSTEM BASED ON PANORAMIC TECHNOLOGY}

The system involves an online learning system of panoramic mode and special pen. The system contains four parts of the panoramic courseware, namely, making system, playing system, assignment interaction, and laboratory system.

\section{A. Panoramic courseware making system}

First, the making system of the panoramic courseware chooses teaching materials, from which it selects panoramic pictures as panoramic multimedia courseware. Meanwhile, teachers' explanation content, PPT data, and all other materials are recorded into the data structure. Then, professional personnel carry out the post production with data processing system. Teaching voice, explained movements, and PPT are matched, and finally the courseware that complies with the making norms of panoramic learning forms through the data processing system. The system then orders the processing of these data ac-

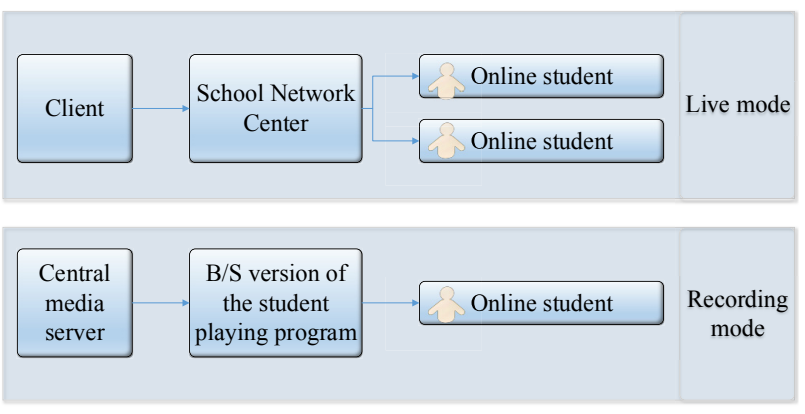

Figure 2. Simple process chart of panoramic courseware playing system

cording to chapters, and uploads the file for examination and approval. The reviewers check whether the courseware conforms to standards or not. The unqualified courseware will be rejected, and its maker will be informed to modify it. The qualified courseware will enter the school network center for publication in public and in the internal school network. Students in school can browse online or download the content of the learning course. The simple process chart of the making system of the panoramic courseware is shown in Figure 1.

\section{B. Panoramic courseware playing system}

The playing system of the panoramic courseware reads the courseware that complies with making norms and norms from the school network center and analyzes it, as well as makes teachers' voice, PPT materials, and explained movements in the form of recorded or live playing. This way, students can be personally on the scene to reach the purpose of panoramic simulation of classroom teaching. In the live playing process, teachers' voice is synchronously broadcasted through the center media server in the form of media stream. Students online receive movement and voice signals through a special client and synchronously play those signals on their computer, reaching the purpose of live teaching. This system can intensively put the normative courseware on the center server through recording. Students can choose topics of their interest and learn through online browsing and downloading through a special client or a special studentplaying process of $\mathrm{B} / \mathrm{S}$ version. Fig. 2 shows a simple process chart of the playing system of the panoramic courseware.

\section{Panoramic assignment interaction system}

The panoramic assignment interaction system can make teachers and students interact. With this system, the teacher can arrange homework and send it to students online. Students can directly answer questions on the assignment courseware with their panoramic learning pen and upload their answers to the center server to generate the sole file 




number. Then, the school network center releases the assignment courseware to the teacher. After receiving students' answers, the teachers correct and grade the assignments. Afterward, reviewer's code is generated, and the assignments are returned to students. After receiving the corrected assignments, students can utilize the playing function of learning system for the correction voice and movements and know their own learning effects. Fig. 3 shows a simple process chart of the panoramic assignment interaction system.

\section{Application exhibition of online learning system}

The application exhibition of online learning system based on panoramic technology is shown in Figures 4 and 5 .

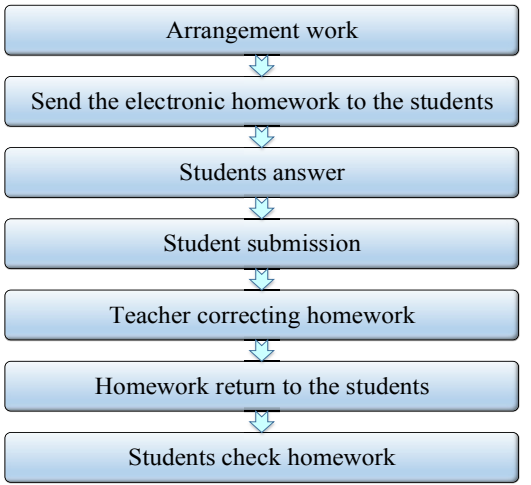

Figure 3. Simple process chart of panoramic assignment interaction system



Figure 4. Interface effect I of online learning system based on panoramic technology

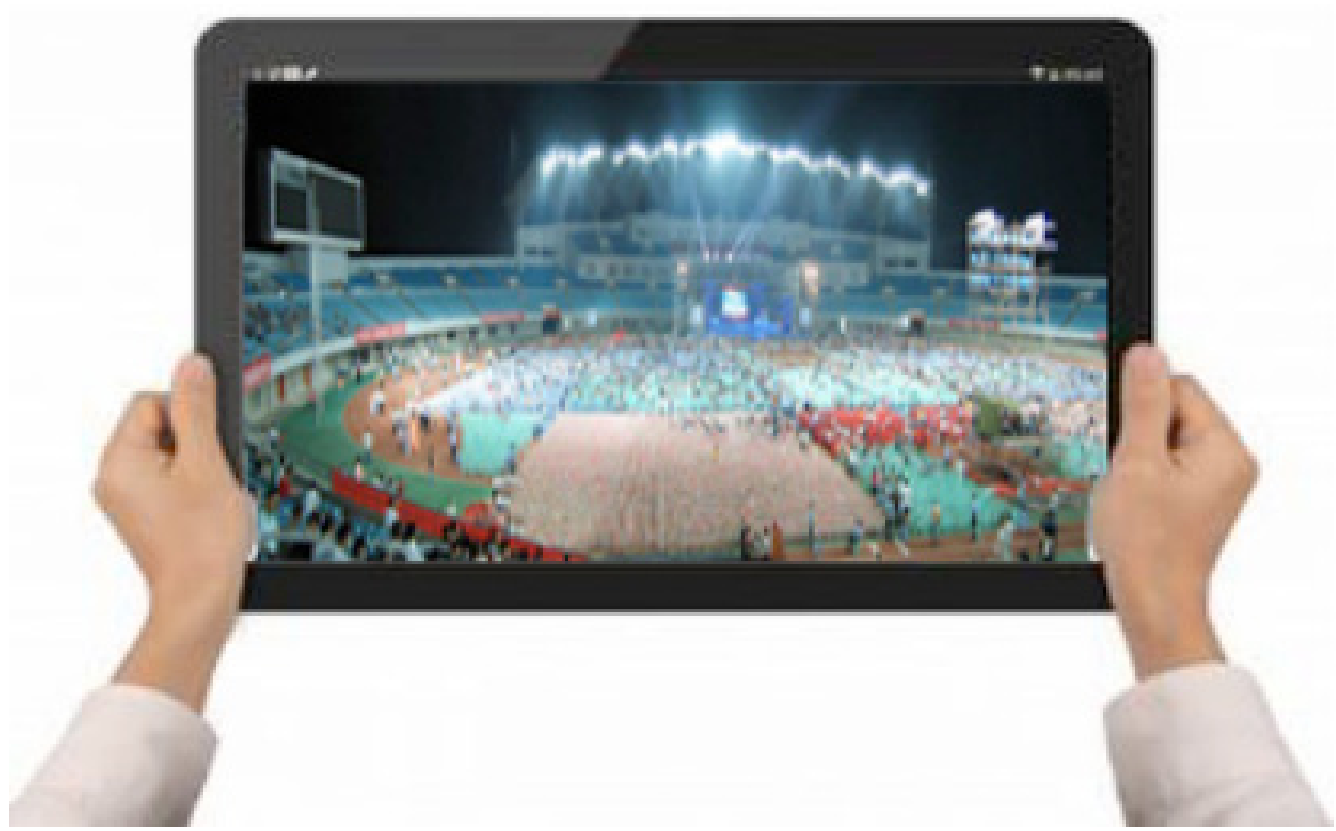

Figure 5. System Interface effect II of online learning system based on panoramic technology 


\section{APPLICATION OF ONLINE LEARNING SYSTEM BASED ON PANORAMIC TECHNOLOGY IN SPORT PSYCHOLOGY TEACHING}

We randomly selected 100 students of the same specialty in School of Physical Education in Fujian Province to verify the application effect of the leaning system of panoramic mode in teaching sport psychology. Fifty students were selected as the experimental group, and the other 50 students served as the control group. The control group learned through traditional teaching mode, wherein the teacher taught them using traditional PPT and arranged assignments in the classroom. Conversely, the experimental group learned online using the panoramic mode. After the course ended, we compared the student evaluation in both groups on the teaching effect, as well as the scores in theory test and sport skill.

Student evaluation on the teaching effect in both groups is shown in Table 1 . The students in the experimental group taught with the panoramic system are superior to the ones in the control group taught with traditional teaching method in terms of course interest, panorama understanding, independent learning wish, and practical application. This indicates that the panoramic system can deepen the understanding of concepts and contents in the course. Students' learning initiative is motivated significantly. The effect of interactive learning effect is also significant. The students taught with traditional method consider that the learning content of psychology is abstract and difficult, and that the contents of teaching materials are dull. Thus, their learning interest is low, and it is hard for them to apply what they have learned in practical situations.

The comparison of examination scores is shown in Table 2. The students in the experimental group are superior to those in the control group in terms of theory and sport skill scores. Students can deepen their course understanding and strengthen their theoretical knowledge through panoramic technology. Conversely, the experimental group performs well in sport skills. This means that the system can promote students to combine abstract theoretical knowledge of psychology with practical sport training and competitions, which contributes to creating excellent sport performance.

The previously presented results prove that online learning system based on panoramic technology is effective in teaching sport psychology and can offer considerable help for students to better learn this course.

\section{CONCLUSION}

Sport psychology is a specialized foundation source of school of physical education. This study constructed an online learning system based on panoramic technology for sport psychology course to make students learn this course more effectively. This study mainly investigated the following contents: (1) introduction and analysis of online learning system based on panoramic technology and its advantages in teaching; (2) and introduction and analysis of functions of each module involved in this system. This system mainly includes making, playing, assignment interaction, and laboratory systems of the panoramic courseware. These systems can be implemented through special panoramic learning pen. We also investigated the (3) practical application effect of this system in sport psychology course. Results show that this system can enhance students' interest in sport psychology and understanding of theoretical knowledge, and promote independent learning. In addition, with this system, students' performance in the theoretical course and sport skill performance increases. This indicates that the online learning system based on panoramic technology can facilitate students in applying theoretical knowledge of psychology in practical sport training and competition. In conclusion, the online learning system based on panoramic technology is effective for teaching sport psychology and improves teaching quality, generally. Therefore, it deserves to be promoted.

TABLE I.

COMPARISON OF EVALUATION OF BOTH GROUPS ON TEACHING EFFECT

\begin{tabular}{|l|c|c|c|c|c|c|}
\hline \multirow{2}{*}{\multicolumn{1}{|c|}{ Item }} & \multicolumn{3}{c|}{ Control group $(\boldsymbol{n}=\mathbf{5 0})$} & \multicolumn{3}{c|}{ Experimental group $(\boldsymbol{n}=\mathbf{5 0})$} \\
\cline { 2 - 8 } & Improve significantly & Improve & Not improve & Improve significantly & Improve & Not improve \\
\hline Course learning interest & 2 & 8 & 40 & 38 & 7 & 5 \\
\hline understanding of panorama & 5 & 7 & 38 & 40 & 6 & 4 \\
\hline independent learning wish & 2 & 6 & 42 & 36 & 7 & 7 \\
\hline Practical application & 3 & 2 & 45 & 38 & 5 & 7 \\
\hline
\end{tabular}

TABLE II.

COMPARISON OF THEORY AND SPORT SKILLS OF BOTH GROUPS

\begin{tabular}{|l|c|c|c|}
\hline \multicolumn{1}{|c|}{ Group } & $\boldsymbol{n}$ & Theory score & Sport skill score \\
\hline Control group & 50 & $81.2 \pm 3.7$ & $78.5 \pm 2.0$ \\
\hline Experimental group & 50 & $86.0 \pm 7.2$ & $87.4 \pm 3.6$ \\
\hline$t$ & & -4.18 & -15.28 \\
\hline$P$ & & $<0.01$ & $<0.01$ \\
\hline
\end{tabular}


PAPER

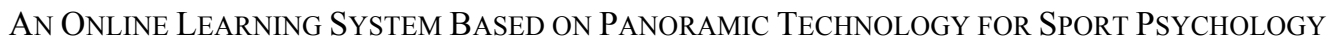

\section{REFERENCES}

[1] Toros T., Salman M., Sarı İ., "The comparison of sports coaches' pre-season, in-season and post-season leadership behaviours in terms of sport psychology," Journal of Human Sciences, vol. 10, no. 1, pp. 237-245, May 2013.

[2] Li M.L., Nie J.S., Ren Y.J., "Effects of exercise dependence on psychological health of Chinese college students," Psychiatria Danubina, vol. 27, no. 4, pp. 413-419, December 2015.

[3] Griff E.R., Matter S.F., "Evaluation of an adaptive online learning system," British Journal of Educational Technology, vol. 44, no. 1, pp. 170-176, January 2013. http://dx.doi.org/10.1111/j.14678535.2012.01300.x

[4] Peng Q.Z., "Design and Research on the Network Tutoring System of Information Retrieval Curriculum," Library and Information Service, vol. 51, no. 7, pp. 79-82, July 2007.

[5] Buttner E.H., Black A.N., "Assessment of the Effectiveness of an Online Learning System in Improving Student Test Performance," Journal of Education for Business, vol. 89, no. 5, pp. 248-256,

2014. http://dx.doi.org/10.1080/08832323.2013.869530

[6] June L.E.E., Yoon S.Y., Lee C.H., "Exploring Online Learning at Primary Schools: Students' Perspectives on Cyber Home Learning System through Video Conferencing (CHLS-VC)," TOJET: The Turkish Online Journal of Educational Technology, vol. 12, no. 1, pp. 68-76, January 2013.

[7] Lo J.J., Chan Y.C., Yeh S.W., "Designing an adaptive web-based learning system based on students' cognitive styles identified online," Computers \& Education, vol. 58, no. 1, pp. 209-222, January 2012. http://dx.doi.org/10.1016/j.compedu.2011.08.018
[8] Lautala P.T., Haas P.J., Velat J.L., "High Speed Rail Learning System (HSRLS)-Taking Advantage of Online Technologies in Railway Education," International Journal of Transportation Science and Technology, vol. 4, no. 2, pp. 179-196, June 2015. http://dx.doi.org/10.1260/2046-0430.4.2.179

[9] Haider M., Singh M., Triar U., "An investigation of any correlation amongst cognitive styles, cognitive traits, and performance of learners for developing a generalized semantic framework for adaptive online learning system," International Journal of Computer Science Issues, vol. 9, no. 3, pp. 241-245, May 2012.

\section{AUTHORS}

Wenxin Xu (Corresponding author) is an Associate Professor at Fujian Normal University, Institute of Physical Education and Sport Science, Fuzhou, 350007, Fujian, China. His research interests include physical education and sport psychology. (wenxin20142014@163.com)

Jiwei Yao is a Professor at Hunan University of Science and Technology, Physical Education Institute, Xiangtan, Hunan, 411201, China. His research interests include physical education and sport psychology. (yaojiwei111@yeah.net)

This work was supported by Ministry of education of humanities and social science youth fund projects (15YJC890041), Fujian province colleges and universities in the new century talents support program (XN1505), Sports philosophy and social sciences research project of the Sport General Administration of China (2081SS14112), and Philosophy and Social science Fund Project in Hunan Province (13YBB083). The authors declare that there is no conflict of interests. Submitted 07 August 2016. Published as resubmitted by the authors 12 September 2016. 